\title{
FUTURO DE LA INTEGRACIÓN EN LA NUEVA CIVILIZACIÓN
}

\section{O FUTURO DA INTEGRAÇÃO NA NOVA CIVILIZAÇÃO}

\section{Eve Rimoldi de Ladmann}

Resumen: Analizo los cambios a los cuales asistimos en el mundo actual, que implican un cambio de civilización. Las nuevas tecnologías de las comunicaciones permiten un acercamiento que supera las distancias así como un mejor conocimiento, influyendo también en las relaciones económicas pasando de "sociedades de producción" a "sociedades del conocimiento". Comprenderlos nos permitirá subsistir como Región. El desarrollo de la comunicación no sólo influye en el sistema político, sino que modifica también las relaciones comerciales.

Los procesos de regionalización no constituyen entonces una creación arbitraria ni un proceso ideológico, sino una respuesta a las nuevas necesidades que pueden advertirse, intentando entonces acercar soluciones a los problemas que han surgido no sólo en los países del tercer mundo.

Resumo: Analiso as mudanças que assistimos no mundo atual, as quais implicam alterações de civilização. As novas tecnologias de comunicação permitem uma aproximação que supera as distâncias e favorece o conhecimento, influindo também nas relações econômicas

\footnotetext{
* Doctora en Derecho y Ciencias Sociales por la Universidad de Buenos Aires. Máster en Economía y Administración de Empresas -Instituto Universitario-ESEADE. Posgrado de Perfeccionamiento del Programa Exterior de la Academia de Derecho Internacional de la Haya. Reconocimientos: Diploma como Profesora Consulta y por los 25 años de labor docente, Facultad de Derecho de la UBA (2007). Premio a la producción Científica y Tecnológica, años 1992, 1993 y 1994, entregado por el Consejo Superior de la UBA. Miembro de numerosos Tribunales de Tesis Doctoral en universidades argentinas y en el extranjero. Directora de diversos becarios. Directora del Seminario Permanente de Becarios del Instituto de Investigaciones Jurídicas y Sociales "Ambrosio L. Gioja" (1994-1995).Directora e investigadora en distintos proyectos de investigación. Integrante de diversos Grupos de Investigación. Proyectos UBACYT. Evaluación de investigadores del CONICET y diversas universidades. Miembro de diversas Sociedades Científicas y Academias Nacionales e Internacionales. Directora de Carreras de Especialización y Cursos de Posgrado. Participación en numerosos Seminarios y diferentes reuniones académicas, como conferenciante, expositora, panelista, coordinadora u organizadora. Directora del Curso de Actualización en Derecho de la Integración y del Mercosur Departamento de Graduados. Facultad de Derecho. UBA (19972009). Autora de numerosos artículos y publicaciones.
} 
passando de "sociedades de produção" a "sociedades de conhecimento". A compreensão dessas mudanças nos permitirá subsistir como Região. $O$ desenvolvimento da comunicação não apenas influi no sistema político, mas também modifica as relações comerciais.

Os processos de regionalização não constituem, assim, uma criação arbitrária nem um processo ideológico, mas uma resposta às novas necessidades que podem surgir, buscando, então, levar soluções aos problemas que surgiram não apenas nos países de terceiro mundo.

Palabras clave: Transición, Cambios, Integración, Asia, Pacífico, Tecnologías, ¿Estado Nación?

Palavras-chave: Transcição, Mudanças, Integração, Ásia, Pacífico, Tecnologias, Estado-nação?

Nuevamente nos planteamos en el dos mil trece si los procesos de integración resultan una solución adecuada al escenario actual. Para dar una respuesta a ese interrogante debemos intentar una descripción de las características de ese escenario, ya que los cambios que se han producido en este milenio son tan profundos que, coincidiendo con quienes lo han manifestado, asistimos a una nueva civilización.

He tratado el tema anteriormente y no puedo dejar de referirme a esos cambios que tornan tan difícil su comprensión a quienes deben tomar decisiones, tanto políticas como económicas ${ }^{1}$.

Ello ocurre no sólo en los países que integramos el Mercosur sino también en los que se han denominado del primer mundo que tratan de construir un nuevo sistema internacional basado en un modelo diferente en sus relaciones, no ya de confrontación sino de competencia, intentando compartir beneficios.

Esa sensación de sentirnos en transición de un período histórico a otro, de una civilización a otra, nos obliga a reformular anteriores conclusiones para desarrollar conceptos nuevos que permitan un mejor entendimiento de los procesos a los cuales nos enfrentamos, teniendo también en cuenta que la inmutabilidad no es una característica de la realidad.

El modelo que se elija para el análisis de esa realidad debe ser sometido a un proceso crítico que permita determinar el grado de

1 RIMOLDI DE LADMANN Eve. Los Procesos de Integración y los Desafíos del Mundo Actual. Las Relaciones Exteriores del Mercosur. Bs. As. Ed. Universidad de Buenos Aires. 2010. 
coincidencia entre la estructura propuesta y la que deriva de los hechos exteriores, para poder advertir las distintas pautas de comportamiento de los subsecuentes períodos históricos.

Si bien no es posible predecir el futuro, la solución de los problemas que enfrentamos se tornará imposible si pretendemos asumirla en forma aislada. Será el obrar en forma conjunta y las alianzas las que aportarán los cambios que habrá que ir adoptando.

Pero esas propuestas y soluciones dependerán no sólo de la capacidad de quienes estudien los problemas y aporten estrategias de cambios sino principalmente, de las pautas culturales de los actores políticos que las tomen.

Se ha desarrollado un movimientos conocido como "acceso abierto en el ciclo de la comunicación científica” que promueve, con propósitos educativos, el derecho a la libre disponibilidad a través de Internet del texto completo de artículos publicados por investigadores manteniendo el reconocimiento de la autoría, lo cual permitiría aumentar el impacto y la visibilidad de los trabajos científicos ${ }^{2}$.

El acceso a la información y al conocimiento no sería actualmente un problema, pero su interpretación puede ser distorsionada por los intereses a los que puedan responder quienes finalmente deciden.

Para comprender esas dificultades me ha parecido útil señalar las características de la civilización en la que vivimos actualmente:

Primera: En el siglo pasado el conflicto entre las dos potencias dominantes (Estados Unidos y la URSS) condicionaba la adhesión de los países.

Sin embargo, aquel mundo bipolar ha desaparecido y se ha desdibujado la clara identificación de las ideologías que lo sustentaban. El desarrollo de los países emergentes no era un tema aún importante en las relaciones internacionales. Sin embargo, a mediados del siglo pasado Europa occidental comprendió que su unión le permitiría alcanzar un progreso económico que la guerra había impedido.

En 1957 se firma el Tratado de Roma y a pesar de los conflictos que han surgido, crearon una Comunidad que fue estrechando sus vínculos hasta firmar el 1 de diciembre de 2009 el Tratado de Lisboa, ratificado

2 EVERETT - GREEN Robert. "Cyberspace” en Book of the Year, Editorial Encyclopedia ritannica. 1996. 
por 25 de los 28 Estados que la integran ${ }^{3}$.

No ha surgido otra Comunidad tan estrechamente ligada. Sin embargo, también avanzan las integraciones en los países de Asia y entre los dos que se encuentran aislados: Australia y Nueva Zelanda.

A estos últimos, el ingreso de Gran Bretaña a la Unión Europea les hizo comprender que su relación económica se vería limitada. Firmaron entonces un Tratado Comercial para el Estrechamiento de la Cooperación Económica entre Australia y Nueva Zelandia e implementaron las normas de la Organización Mundial de Comercio, reduciendo sus tarifas y homogeneizando sus sistemas aduaneros, incluyendo en las negociaciones los servicios y las inversiones; eliminando los subsidios a las exportaciones recíprocas y las barreras no arancelarias y arancelarias, excepto para algunos productos sensibles; eliminaron también las medidas antidumping en el comercio bilateral.

A los países menos desarrollados les reconocen aranceles preferenciales para la importación de bienes producidos o fabricados de ese origen, siempre que al menos el 50\% de los mismos o de sus insumos sea natural de la región. Es el caso de los productos del Mercosur.

No se detiene allí el desarrollo de las relaciones económicas en el continente asiático y me parece útil referirme a ellas aunque brevemente, para compararlas con el desarrollo de las mismas en América Latina.

a) Finalizada la Guerra Fría y pacificada la Región, se decidió establecer una Zona de Libre Comercio Asiática (AFTA o Asia Free Trade Agreement), con una Tarifa Común de Preferencias Efectivas (CEPT según su sigla en inglés), firmando en Singapur el Tratado de Amistad y Cooperación en el Sudeste Asiático por el que se acuerda una rebaja tarifaria en quince años que llevaría los aranceles entre 0 y $5 \%$ intra - región.

Esa meta se logró en el 2003 para el 87 \% de los productos, aunque quedaron excluídos los servicios, las materias primas de origen agrícola y los productos primarios no elaborados. Ese mercado ha crecido a partir de un notable aumento de la producción industrial.

b) Debemos considerar también a la Asociación de Naciones del Sudeste Asiático (ASEAN) que surge con la Declaración de Bangkok que firman Filipinas, Indonesia, Malasia, Singapur y Tailandia, reemplazando a la Association of Southeast Asia (ASA)

3 El último país en incorporarse a la Unión Europea ha sido Croacia en el 2013. 
que habían constituído en 1961 Filipinas, Malasia y Tailandia.

Creada en 1967, Brunei Drussalam se incorpora posteriormente al independizarse en 1984 y como observadores primero y luego como miembros plenos lo hicieron Camboya, Vietnam (julio de 1995), Myanmar y Laos (1997), completándose así el número de los diez países del Sudeste asiático que integran la Asociación, con una población que según cifras aproximadas sería de 566.932.715 habitantes ${ }^{4}$.

Es país observador Papúa Nueva Guinea. Asimismo han firmado un Acuerdo de Cooperación con la Unión Europea y constituyeron un Foro conjunto con Japón, Corea del Sur y China.

Se han fijado los fundamentos del Acuerdo:

- Promover el desarrollo económico, cultural y social mediante programas de cooperación que les permitieran incrementar sus ventajas competitivas para llegar al mercado mundial, constituyendo un referente de consulta necesaria en cualquier proyecto.

- Respeto mutuo de su independencia, soberanía, igualdad, integridad territorial e identidad nacional.

- Derecho de cada Estado de conducir su existencia nacional libre de interferencias externas, subversión o coerción, sin intervención en los asuntos internos de cada uno.

- Solución mediante medios pacíficos de diferencias y disputas, renunciando a la amenaza o uso de la fuerza.

- Efectiva cooperacion entre ellos. Se prefirió no establecer una estructura formal permanente. Las decisiones son inter gubernamentales y han sido previstas:

- las Reuniones de Jefes de Gobierno cada tres años, para fijar las directivas de la Asociación;

- las Reuniones de Ministros de Relaciones Exteriores, Economía y de otras carteras en caso necesario, para proponer lineamientos políticos y coordinar actividades;

- Reuniones Consultivas Conjuntas, donde se tratan temas como

4 Según cifras estimadas de la Oficina del Censo de Estados Unidos. 
preservación del medio ambiente, desarrollo social, ciencia y tecnología, cultura e información, industria, minerales y energía, drogas, turismo y asuntos legales;

- Un Foro Regional (ARF) al que invitan a países extra-zona, para debatir temas políticos y de seguridad, propuesto en la Reunión del 23/24 de julio de 1993;

- Reuniones posteriores a las celebradas en el más alto nivel intraregional, con representantes de los países de la APEC, de la Unión Europea, Rusia y Laos en lo que ha dado en llamarse una "diplomacia preventiva".

- Asimismo fue propuesta una iniciativa: la Alianza Estados Unidos - ASEAN, surgida en la Reunión de APEC de noviembre de 1993, comenzó a implementarse al año siguiente. Tiene sólo un alcance comercial basado en el interés de Estados Unidos en eliminar las barreras comerciales existentes y revertir su deficit en el intercambio con la región.

ASEAN mantiene representaciones en 12 países, los Comités ASEAN en los cuales se estableció un mecanismo de diálogo. Ninguno de ellos es de América Latina. Un Secretario General, con rango de Embajador y status ministerial, con sede en Indonesia, coordina las actividades de las Conferencias o Reuniones y de los Comités.

En julio del 2001 en la Conferencia Ministerial organizada por Vietnam, se acordó intensificar la integración y ampliar la cooperación, incluyendo una convocatoria a países extra - regionales, invitándolos a su adhesión al Tratado de Amistad y Cooperación.

En la Reunión se propuso la celebración de una Segunda Cumbre en la ciudad de Cebu, Filipinas. En esa 12 th Reunión de la ASEAN del 13 de enero de 2007, los Jefes de Estado o de Gobierno de Brunei, Camboya, Indonesia, Laos, Malasia, Myanmar, Filipinas, Singapur, Thailandia y Vietnam decidieron crear una sola Comunidad en el 2020.

c) Resulta también de interés en Asia Pacífico una referencia a la APEC (ASIAN PACIFIC ECONOMIC COOPERATION) ${ }^{5}$.

En las reuniones anuales que se realizaron han participado países de la cuenca del Pacífico y de Oceanía tanto de Asia como de América: Australia, Brunei, Canadá, Corea del Sur, Chile, la República Popular

5 www.apec.org. 
de China, Filipinas, Indonesia, Japón, Malasia, México, Nueva Zelandia, Papua Nueva Guinea, Singapur, Tailandia, Taiwan y Estados Unidos ${ }^{6}$. Se incorporaron en noviembre de 1999 Rusia, Vietnam y Perú. Lo solicitaron asimismo Ecuador,India, Macao, Pakistán y Sri Lanka.

Las diferencias estructurales, culturales y económicas que existen entre ellos, no permitieron crear órganos permanentes por lo cual se adoptó una institucionalización flexible, intergubernamental y funcional.

Se reúnen periódicamente desde 1993 los Líderes de cada país; los Ministros de Relaciones Exteriores y Comercio cuyo objeto es aprobar el programa de trabajo y su presupuesto.

La Secretaría Administrativa, que tiene su sede en Singapur, es financiada por su gobierno. Su director ejecutivo es secundado por un staff profesional.

Adoptaron también los principios de la Convención de Kyoto sobre prácticas aduaneras y el uso del UN/EDIFACT estándar para los procedimientos aduaneros.

Con el objeto de evitar confrontaciones se firmaron una red de acuerdos mutuos de reconocimiento en diversas áreas (productos eléctricos; alimenticios; programa de desarrollo de infraestructura técnica entre otras) y un régimen de controversias.

Avanzaron en la liberalización del comercio y las inversiones y en la adecuación de sus normas mediante la convergencia, de acuerdo a las recomendaciones propuestas en el nivel regional ${ }^{7}$.

La Región Asia Pacífico aparece involucrada en otras organizaciones interna-cionales buscando el progreso de sus relaciones a traves del diálogo. Sólo las menciono:

El PECC (PACIFIC ECONOMIC COOPERATION COUNCIL) $)^{8}$ fundada en 1980 por una propuesta de los Primeros Ministros Malcom Fraser (Australia) y Massayoshi Ohira (Japón).

6 htpp://www.apecsec.org.sg.

7 Ver YAMAZAWA Ippei. "Ecotech y FEEEP: la agenda pendiente de APEC" en SELA Relaciones de América Latina y el Caribe con Asia Pacífico. (1997 - 1998- INTAL - BID. Ed. CORREGIDOR. Buenos Airess. 1999. Cap. VI.

8 Las siglas de las organizaciones se citan en inglés por resultar la forma habitual de hacerlo y permitir así su identificación. Su traducción al español es Consejo de Cooperación Económica del Pacífico. 
EAEC (EAST ASIAN ECONOMIC CAUCUS), iniciativa de Malasia para permitir a la región exclusivamente asiática la mejor defensa de sus intereses, aunque no fue concebido como un bloque comercial. Formaban parte en la primera reunión a fines de 1990, seis miembros: Indonesia, Malasia, Filipinas, Singapure, Tailandia y Brunei.

PBEC (PACIFIC BASIN ECONOMIC COUNCIL), una iniciativa privada que surge en 1967 como organización empresarial integrada por corporaciones de los países de la región del Pacífico (Australia, Canadá, Chile, Corea, Estados Unidos, Fidji, Filipinas, Hong Kong, Japón, Malasia, Mexico, Nueva Zelandia, Perú y Taiwan, que se ha ido ampliando). Se adoptó una simple estructura institucional, con una Secretaría Internacional con sede en Honolulu que coordina sus actividades y presta apoyo logístico; un Comité Directivo, que orienta el desarrollo de tareas y presta asistencia a las empresas; los Comités locales que se agrupan por sectores de áreas de producción y de servicios, incluyendo estos últimos a las Universidades e Institutos de investigación.

FOCALAE (EALAF O EAST ASEAN LATIN AMERICA FORUM) 9 Fué propuesta en 1998 por el Primer Ministro de Singapur Goh Chok Tong, para promover el diálogo inter - regional.

El ha expresado: "Yo concebí al EALAF como un diálogo de múltiples dimensiones"10. Su objeto sería "eliminar "las barreras psicológicas" que la Discurso pronunciado por el Primer Ministro Goh Chok Tong el 2 de junio de 1999 en el CARI.

Para los países que integran el MERCOSUR la diversificación de las relaciones inter - regionales les permitirían ampliar el espacio de participación en los debates de los problemas comunes que deben enfrentar.

Los fracasos son siempre costosos. Como sostenía Bismark sólo un loco aprende de su propia experiencia. Una persona sensata aprende de la experiencia de los demás.

Para ampliar el desarrollo, hace falta tanto estabilidad institucional como una apropiada conducción política transparente.

Segunda: Otra característica de la civilización actual podemos

9 Su sigla en español es FOCALAE (Foro de Cooperación America Latina - Asia del Este).

10 Discurso pronunciado por el Primer Ministro Goh Chok Tong el 2 de junio de 1999 en el CARI. 
advertirla en las dificultades que tienen las fronteras convencionales del Estado Nación para limitar el avance en su territorio de problemas que sólo podrán superarse mediante la cooperación de sus soberanías.

Esa estructura política del Estado Nación surgió por los cambios que la civilización industrial exigió: la producción en serie que sustituyó a la producción artesanal, requería el ejercicio de la autoridad en el territorio donde se instalaban las nuevas industrias, con la producción en gran escala que sustituyó a los pequeños talleres.

Aparece la fábrica y con ella las concentraciones urbanas, transladándose a otras instituciones sociales: escuelas para los niños, hospitales para los enfermos, cárceles para los delincuentes ${ }^{11}$. Se produce también una concentración del poder económico y del capital necesario para invertir en las industrias y las nuevas estructuras intermedias del comercio, tanto en Occidente como en los países comunistas donde la concentración de capital está a cargo del Estado.

Los cambios que advertimos en la civilización actual ¿exigen también nuevas relaciones entre los Estados? ¿Representan un nuevo desafío? ¿Puede considerarse el comienzo de una "civilización" diferente? No tengo la respuesta, pero me parece de interés referirme a esos cambios, para lo cual señalo algunos:

a) Las migraciones masivas y los asentamientos periféricos en las grandes ciudades. Es un problema que se agrava ante el crecimiento de grupos que son introducidos mediante redes que obtienen ganancias importantes de su actividad ilegal. Buscan mejores condiciones de vida, que no siempre obtienen o bien huyen de enfrentamientos internos. Los requerimientos para su adaptación exigen prestaciones de educación, capacitación, salud, vivienda y trabajo que debiera asumir cada Estado receptor.

b) La lucha contra el terrorismo internacional así como la lucha contra la delincuencia transnacional. Al Estado Nación le resultan ineficaces las decisiones que toma para proteger las fronteras, que en el caso del narcotráfico ha producido redes globales que representan un desafío para la organización política actual y al concepto mismo de frontera.

Deben incluirse también actividades en áreas como las finanzas, la banca, las inversiones o el lavado de dinero para las cuales tampoco las fronteras nacionales representan un límite.

11 TOFFLER Alvin. La Tercera Ola. 
c) Las crisis económicas. La transnacionalización de problemas incluye también a los mercados financieros, crediticios e inmobiliarios. No ha sido la del 2008/2009 la primera que ha ocurrido en el mundo, aunque sí la que ha tenido tal alcance extendiéndose tanto en países desarrollados como a los que se encuentran en etapas de desarrollo, obligando a los gobiernos a intervenir y adoptar medidas de salvataje de empresas públicas $y$ privadas sin que hubiera una regulación adecuada de las calificadoras de riesgo que advirtieran los peligros.

d) Los cambios en la elaboración de productos, que en la era industrial anterior se completaban en una fábrica de un Estado determinado y hoy se integran mediante la producción de partes para un armado final en otro Estado. Un ejemplo es la producción de autos o el abastecimiento de recursos primarios y energéticos que atraviesan incluso las fronteras nacionales. Argentina y Brasil comparten esas condiciones.

e) Los cambios han sido notables también en el medio ambiente y la polución. Ya fueron planteados en un estudio realizado por iniciativa del Club de Roma, publicado en 1977 sobre Los Límites al Crecimiento. Señalaron en ese trabajo, las tendencias a largo plazo que se advertían en el agotamiento de los recursos y los daños al medio ambiente: contaminación, cambio climático; escasez en la provisión de agua y alimentos entre otros.

Se han firmado algunos acuerdos internacionales: podemos mencionar: el Tratado de 1992 sobre Cambio Climático, en el cual los países asumen el compromiso de "evitar peligrosas interferencias antropogénicas en el sistema climático"; el Protocolo de Kyoto” de 1997, aún no ratificado por todos los Estados aunque sí lo hicieron los Estados Miembros del Mercosur, incluyendo Venezuela.

En 2009, tuvo lugar en Copenhague la 15a Reunión Anual de la Conferencia de las Partes de la Convención Marco de las Naciones Unidas, con la presencia de 119 jefes de Estado y 15.000 delegados de diferentes naciones.

En ella, Japón propuso una mayor meta en la reduccíón de gases contaminantes y Brasil, entre los Miembros del MERCOSUR, comunicó la aprobación por su Congreso de una ley que establece la reducción de emisiones. El entonces Presidente, Luis Ignacio Lula da Silva, anunció la disposición del país de colaborar con fondos propios para la lucha que desarrollen los países con menos recursos. Sin embargo, no se logró en 
esa ocasión un acuerdo vinculante.

Se han realizado veintiocho Conferencias sobre cambio climático. Una nueva reunión de la Conferencia, la No. XVI se celebró en Cancún, Mexico, en el 2010 y la última hasta el presente, en Catar en el 2012.

En el mes de junio de este año 2013, tuvo lugar en Bonn el 38 período de sesiones de los Organos Subsidiarios de Ejecución y de Asesoramiento Científico y Tecnológico previstos en el Protocolo de Kyoto que revieron las modalidades y procedimientos de desarrollo de los mecanismos de mantenimiento de la limpieza ambiental y aprobaron un plan de desarrollo y transferencia de tecnología e implementación de mecanismos tecnológicos ${ }^{12}$.

f) Podemos incluir en los cambios la expansión de amenazas a la salud, que afectan a poblaciones enteras y exigen una acción coordinada de los diferentes países y ponen también a prueba la capacidad de los Estados para darles una solución.

Las decisiones que deben adoptarse representan costos que asumirá cada Estado afrontando los gastos de asistencia sin sacrificar los objetivos fundamentales de calidad, equidad y crecimiento.

Tercera: A pesar de considerarlos esenciales, he dejado para el final referirme a los medios audiovisuales y las nuevas tecnologías que han provocado cambios tanto en las estructuras políticas como en las sociales, difundiendo valores e ideas que se aceptan como realidades.

La Revolución Tecnológica en las Telecomunicaciones nos permite conocer de inmediato los acontecimientos que ocurren en cualquier parte de nuestro planeta, no a través del discurso "oficial" sino de las cámaras que nos acercan los hechos por los medios electrónicos y la creación de los espacios virtuales, como "Facebook"; "Flickr" (almacenaje e intercambio de videos y fotos); "Youtube" (para compartir videos); "Twiter" entre otros, los cuales impiden ocultar la verdad de los acontecimientos. La posibilidad de disponer de nuevos componentes electrónicos de menor costo, mayor eficiencia y rapidez por la utilización del grafeno, un elemento flexible y doscientas veces más resistente que el acero y con más alta conductividad térmica y electrónica ampliará esas condiciones.

12 La Corte Suprema de Justicia de Argentina ha dictado un fallo en 2008 Martínez, Beatriz Silvia y otros, en el cual ejerciendo sus facultades implícitas, avanza en la consideración del problema de contaminación de la cuenca La Matanza Riachuelo. 
El desarrollo de la comunicación no sólo influye en el sistema político, sino que modifica también las relaciones comerciales. Las nuevas tecnologías de las comunicaciones permiten un acercamiento que supera las distancias así como un mejor conocimiento, influyendo en el cambio de las "sociedades de producción" a las "sociedades del conocimiento". Aparece asimismo el concepto de "market space" que supera el anterior de "market place".

La influencia es notoria en las relaciones económicas. De la misma manera en que la producción industrial se desmasifica, se produce una adaptación personificada a los gustos del consumidor que deben ser satisfechos mediante la oferta de canales de información en la televisión por cable y digital; en internet, mediante la creación de espacios en temas específicos y por la capacidad de las computadoras de comunicarse. El usuario ya no es un espectador sino que puede participar hasta constituirse en protagonista del intercambio de información.

Esa interconexión ha permitido también identificar aspectos de la realidad que ocurre tanto en los países desarrollados como en aquéllos que no han alcanzado esa etapa y a los cuales me he referido: la escasez de los recursos energéticos, los problemas ambientales; la desforestación y el cambio climático; los recursos para mantener los servicios de salud y la proyección de la edad. Nuevamente podemos comprobar que las fronteras nacionales no impiden la expansión de esos problemas.

Asimismo podemos advertir una mayor presencia de la opinión pública que se expresa no solo en las cuestiones nacionales sino también frente a problemas que atañen a otros países, a partir de las posibilidades de información y comunicación que ofrecen las nuevas tecnologías de la imagen, que dejan una huella profunda. Sin embargo, en algunos casos esos cambios no han sido comprendidos por quienes ejercen el poder político, que no reflejan en sus discursos y decisiones los cambios producidos. Al Estado Nación le resulta difícil, si no imposible, controlar las redes de información y los canales de comunicación que los adelantos actuales hicieron posible. Las prohibiciones que intentan no alcanzan a las transmisiones vía satélite que recorren el mundo por encima de las fronteras. El usuario ya no es un espectador sino que puede participar hasta constituirse en protagonista del intercambio de información. Esas diferencias deben tenerse en cuenta por quienes ejercen el poder político y económico, no enfrentando a los Estados, sino logrando la integración de las soluciones ${ }^{13}$.

13 EVERETT - GREEN Robert. “Cyberspace” en Encyclopedia Britannica, Book of theYear, Estados Unidos1996, p.158. 
En nuestra Región podemos señalar algunas características que debieran tenerse en cuenta para lograr el desarrollo ${ }^{14}$ : a) la creación de una red de seguridad social eficiente y de bajo costo. En general, la proporción de los gastos en seguridad social es mayor en América Latina que en Europa a pesar de su ineficacia para alcanzar los objetivos; b) la profesionalización de la administración pública mediante adecuados programas de entrenamiento; c) la eliminación del clientelismo y las conexiones - en ocasiones poco claras- entre los sectores públicos y privados; d) la erradicación de la pobreza mediante un diseño institucional de proyectos en los que se involucren los gobiernos centrales y locales mediante reglas claras; e) la defensa de la competencia para asegurar un gobierno corporativo prudente debe ser tarea tanto del estado como de la sociedad civil; f) la importancia que debe darse a las pequeñas y medianas empresas en el desarrollo económico y su dinamismo tanto por su contribución en la creación de empleos como en canalizar habilidades empresariales. Para ello debieran simplificarse los procedimientos burocráticos creando canales apropiados de información entre la administración pública y los empresarios; lograr mejores posibilidades de acceso a una financiación accesible; incorporar nuevas tecnologías, capacitando para utilizarlas.

Los procesos de regionalización no constituyen una creación arbitraria ni un proceso ideológico, sino una respuesta a las nuevas necesidades que pueden advertirse, intentando entonces acercar soluciones a los problemas que han surgido no sólo en los países del tercer mundo.

\section{Referencias bibliográficas}

ABREU BONILLA Sergio, PASTORI FILLOL Alejandro (1992) Uruguay y el Nuevo Orden Mundial. Montevideo: Fondo de Cultura Universitaria.

AGUILAR MONTEVERDE Alonso (2002) Globalización y Capitalismo. México: Plaza \& Janés.

BAUMAN Zygmunt (2002) La globalización: consecuencias humanas. 2da ed. México: Fondo de Cultura Económica.

BOBBIO Norberto (1998) Estado, gobierno y sociedad. Por una teoría general de la política. Buenos Aires: Editorial Fondo de Cultura Económica.

14 Fueron señaladas en una Reunión organizada por el Gobierno de Japón en Tokio el 7/8 de marzo de 2002. 
CAI Cuihong \& NI Shixiong (2007) "Is knowledge society possible in the international arena? a constructive interpretation of china's strategic culture" en China International Studies (2), p. 142-157.

CAPALDO Griselda, SHECKMANN JaN CLERICO Laura (dir) (2012) Internacionalización del Derecho Constitucional, Constitucionalización del Derecho Internacional. Buenos Aires: Ed. Eudeba.

DEUTSCH Karl W. (1980) Los Nervios del Gobierno. Modelos de Comunicación y Control. Buenos Aires: Editorial Paidós.

DRUCKER Peter F. (1996) La Administración en una Epoca de Grandes Cambios. Buenos Aires: Editorial Sudamericana.

DUVERGER Maurice (1992) Europa de los Hombres. Una metamorfosis Inacabada. Barcelona: Ediciones Paidós.

GHEMAWAT Pankaj (2008) Redefiniendo la globalización: la importancia de las diferencias en un mundo globalizado. Barcelona: Ediciones Deusto.

HUNTINGTON Samuel (2000) Important Role of Culture Prejudice: How Values Influence Human Progress. Xinhua: China Press.

KAPLAN Morton A. (1968) New Approaches to International Relations. Nueva York: Editorial St. Martin's.

MAGARIÑOS Carlos A. (2005) "Una Propuesta en el contexto de los objetivos de desarrollo del Milenio", en Desarrollo Económico y Reforma de las Naciones Unidas. Hacia una Agenda Conjunta para la Acción. Organización de las Naciones Unidas para el Desarrollo Industrial. Consejo Argentino para las Relaciones Internacionales.

MEADOWS Donella el al (1972) Los Límites del Crecimiento. México. Ed. Fondo de Cultura Económica.

NYE Joseph S. (2006) “The Challenges of China” en How to Make America Safe: New Policies for National Security. Ed. Stephen Van Evera. Tobin Proyect.

ORTIZTulioE., PARDO María Laura (coords) (2006) Estado Posmoderno y Globalización. Buenos Aires: Departamento de Publicaciones. Facultad de Derecho. UBA. 
RIMOLDI de LADMANN Eve (2010) Los Procesos de Integración y los Desafíos del Mundo Actual. Buenos Aires: Universidad Nacional de Buenos Aires.

RIMOLDI DE LADMANN Eve (1999) Politica Exterior y Tratados. Argentina. Chile. Mercosur. Buenos Aires: Ciudad Argentina.

ROSENAU J. N. (1980) The Study of Global Interdependence: Essays on the Transnationalization of World Affairs. London: Frances Printer Publishers.

ROSENCRANCE R. (1986) The Rise of the Trading State: Commerce and Conquest in the Modern World. New York: Ed. Basic Books.

TOURAINE Alain (1997) "Pasaje entre dos mundos", en HALPERÍN Jorge (coord) Argentina en el Tercer Milenio. Buenos Aires: Editorial Atlántida.

WALLERSTEIN Immanuel (1980) The Modern World System. New York: Academic Press.

WALTZ Kenneth N. (1998) Teoría de la Política Internacional. Buenos Aires, Grupo Editor Latinoamericano.

WEBER Max (1994) Economía y Sociedad. México: Fondo de Cultura Económica.

WENDT Alexander (2004) “The state as person in international theory," Review of International Studies (30).

YU XINTIAN (2004) Cultural Factors in International Relations. Shanghai Institute of International Studies. 